\title{
Hypolipidemic Effects of Rosa Damascena Mill. Extract in Streptozotocin-induced Diabetic Rats
}

\author{
Tamam Jauhar $^{1}$, Bilqis Inayatillah ${ }^{1}$, Maftuchah Rochmanti², Achmad Basori ${ }^{3}$ \\ ${ }^{1}$ Master program student in Basic Medical Science, Faculty of Medicine, Universitas Airlangga, Surabaya, \\ ${ }^{2}$ Lecturer, Department of Pharmacology, Faculty of Medicine, Universitas Airlangga, Surabaya, ${ }^{3}$ Professor, \\ Department of Pharmacology, Faculty of Medicine, Universitas Airlangga, Surabaya
}

\begin{abstract}
Background: Diabetes mellitus is a chronic hyperglycemic condition with a lot of complication which can lead to death. Vascular complication in diabetes commonly caused by dyslipidemia which characterized by decreased HDL, elevated LDL, Cholesterol and Triglyceride. Rosa damascena- an ornamental plantthoughts to have anti-hyperglycemia and antioxidant effects because of its large amount of polyphenolic components . This study analyzed hypolipidemic activity properties of an ethanol extract of Rosa damascena by measuring the lipid profile using various doses. Methods: This research is experimental study with randomized post-test only control group design. Twenty male Wistar rats divided into 5 groups; The groups were Healthy Control Group (HCG), Diabetes Group (DG), and Extract Group: P1 (250 mg/kgBW), P2 (500 mg/kgBW), P3 (1000 mg/kgBW). All treatment groups were injected by single-dose streptozotocin $50 \mathrm{mg} / \mathrm{kgBW}$ to induce diabetes, and given the Rosa damascena ethanolic extract oral treatment for 2 weeks. Statistical results showed that Rosa damascena significantly decrease cholesterol (58.2 \pm 15.19$)$, LDL $(11 \pm 2.44)$ optimally in dose $250 \mathrm{mg} / \mathrm{KgBW}$ and triglyceride $(96.7 \pm 44.2)$ optimally in dose $500 \mathrm{mg} / \mathrm{kgBW}$ after 14 days. Conclusion: Rosa damascena extract seems to be great candidate for anti-hyperlipidemic drugs.
\end{abstract}

Keywords: Lipid profile, Rosa damascena, Streptozotocin

\section{Introduction}

According to WHO database in $2016,8.5 \%$ diabetes mellitus patients are adults within range 18 years to 65 years old. Diabetes mellitus is a chronic hyperglycemic condition that caused by disruption of insulin secretion, insulin works or even both ${ }^{1,2}$.

This condition escalate morbidity and mortality of diabetes patients which caused by its vascular complication itself ${ }^{3}$. Vascular complication in diabetes divided into microangiopathy and macroangiopathy. These angiopathy could get worse due to atherosclerosis lesion which formed faster than non diabetes patients ${ }^{2}$. Microvascular complications in diabetes are neuropathy, nephropathy and retinopathy; while macrovascular complications are coronary artery disease, peripheral artery disease, artery renalis sclerosis and even stroke ${ }^{4}$.
Dyslipidemia is one of the main factor that contribute forming atherosclerosis lesion marked by poor high density lipoprotein (HDL), elevating low density lipoprotein (LDL) and rising Triglyceride (TG) 2,5

One of the plant that claimed has potency to decrease blood glucose and control lipid profile was red rose (Rosa damascena Mill.) ${ }^{6}$. Red rose contain a large amount of polyphenolic components; some of them are kaemfrol, cyanidine 3,5, D-glucoside, quarcetin, and gallat acid 7. The highest antioxidant activity of anthocyanin in Rosa damascena was cyanidine 3,5, D-glycoseides or known as cyanidine ${ }^{8}$. The cyanidin found to have antihyperglicemia and antioxidant effects ${ }^{7,9}$.

Roses are easy to grow in tropical country like Indonesia, they sprout under upland and lowland between 1500 height above mean sea level ${ }^{10}$. Indonesian Central 
Bureau of Statistic mentioned that roses is one of the ornamental plants which has the second largest harvest area after Chrysanthemum ${ }^{11}$.

The present study aimed at investigating lipid lowering agents of ethanol extract of Rosa damascena with various doses in diabetic rats.

\section{Material and Methods}

\section{Experimental criteria and animals care}

The animals which used in this research were 20 male white rats Wistar Strain, age \pm 12 weeks with body weight between 150-200 grams, all animals were healthy with no handicap which characterized by shining and clean fur, pink mucous membrane around the eyes and agile. The criteria for the exclusion were sick and disabled. If the experimental animals were dead along experiment they went to dropout criteria.

All animal samples were obtained from Department Pharmacology, Faculty of Medicine, Universitas Airlangga. They were kept under laboratory standard condition with temperature 12 hours light/dark cycle. There were 5 cages with size $500 \times 300 \times 150 \mathrm{~mm}$ (length $\mathrm{x}$ width $\mathrm{x}$ height). Each cage consists of 4 rats. They were fed on standard pellets with water ad libitum.

Animal labs were injected with low dose streptozotocin $50 \mathrm{mg} / \mathrm{KgBW}$ protocol. Fasting blood glucose levels were measured 5 days after the injection, if their glucose level are above $200 \mathrm{mg} / \mathrm{dl}$ then it will be considered diabetic. Easy touch glucometers and glucostrip were used to measure fasting glucose levels 12 .

Animals were divided into 5 groups with random sampling. The groups were Healthy Control Group (HCG), Diabetes Group (DG), Rosa damascena Group: P1 (250 mg/KgBW), P2 (750 mg/KgBW), P3 (1000 $\mathrm{mg} / \mathrm{KgBW}$ ). All experiment procedures in this study were approved by the Ethics Committee Faculty of Dental Medicine Universitas Airlangga number 456/ HRECC.FODM/X/2020, Surabaya, Indonesia, and were performed in an ethical manner with strict adherence to the animal research guide and purpose.

\section{Rosa damascena Extract}

100 grams of dried Rosa Damascena was soaked in $96 \%$ ethanol solution for $3 \times 24$ hours before it was evaporated at temperature of $50^{\circ} \mathrm{C}$ to get viscous extract. This extract was added with CMC-Na $0,1 \%$ to increase viscosity and prevent particle from clotting ${ }^{13}$.

The extract will be given in three different doses which are P1 as much as $250 \mathrm{mg} / \mathrm{kgBW}, \mathrm{P} 2$ as much as $500 \mathrm{mg} / \mathrm{kgBW}$, and $\mathrm{P} 3$ as much as $1000 \mathrm{mg} / \mathrm{kgBW}$. Ethanol extract dissolved with destilled water before giving to rats orally.

\section{Biochemical Analysis}

After 14 days treatment, blood plasma was examined to measure the lipid profile each unit sample. Procedure was required anesthesia and termination since it was using cardiac puncture technique. Blood was collected into vacutainer plastic serum tube using $5 \mathrm{ml}$ syringe with $23 \mathrm{G}$ needle. All blood samples were sent to Surabaya Health Center Laboratory to be analyzed using automatic analyzer.

\section{Statistical Analysis}

Lipid profile from each group were expressed as mean \pm SD. The data were statically analyzed using Anova (normal distribution) and Kruskall Wallis (abnormal distribution) continue with post hoc test with multiple comparison every each group. Values of $p<0.05$ were considered significant ${ }^{14}$. 


\section{Results}

\section{a. Cholesterol}

Table 1. Effect of ethanol extract of Rosa damascena on cholesterol (mg/dl) in streptozotocin-induced diabetic rats.

\begin{tabular}{|c|c|c|c|}
\hline Group & N & X SD & Median (Min-Max) \\
\hline HCG (Health Control Group) & 4 & $64.5 \pm 3.10 \mathrm{a}$ & $65.5(60-67)$ \\
\hline DG (Diabetes Group) & 4 & $138.5 \pm 38.72 \mathrm{~b}$ & $59.5(41-73)$ \\
\hline P1 (Extract RD 250 mg/kg BW) & 4 & $58.2 \pm 15.69 \mathrm{a}$ & $67(54-72)$ \\
\hline P2 (Extract RD 500 $\mathrm{mg} / \mathrm{kg} \mathrm{BW})$ & 4 & $65 \pm 7.74 \mathrm{a}$ & $57.5(51-81)$ \\
\hline P3 (Extract RD 1000 $\mathrm{mg} / \mathrm{kg} \mathrm{BW})$ & 4 & $61.7 \pm 13.2 \mathrm{a}$ & \\
\hline
\end{tabular}

Noted: superscript showed significance difference between groups with $\alpha=0.05$

The lowest cholesterol level was found in group P1 (60.4 14.5$)$ followed with group P3 (62 \pm 11.4$)$ and P2 (65.8 \pm 6.9 ). All groups cholesterol mean was analyzed with Anova followed with Brown-Forsythe and post hoc Games-Howell. Since Games-Howell test showed there was no differences, independent sample $t$ test was carried out. The result was there are significant differences between diabetes group, health control group and treatment group.

\section{b. High Density Lipoprotein (HDL)}

Table 2. Effect of ethanol extract of Rosa damascena on HDL (mg/dl) in streptozotocin-induced diabetic rats

\begin{tabular}{|c|c|c|c|}
\hline Group & $\mathrm{N}$ & $\mathrm{X} \pm \mathrm{SD}$ & Median (Min-Maks) \\
\hline HCG (Health Control Group) & 4 & $30.8 \pm 0.81$ & $30(29-31)$ \\
\hline DG (Diabetes Group) & 4 & $31.2 \pm 3.40$ & $30.5(28-36)$ \\
\hline P1 (Extract RD 250 $\mathrm{mg} / \mathrm{kg} \mathrm{BW})$ & 4 & $28.2 \pm 5.12$ & $28(23-34)$ \\
\hline P2 (Extract RD 500 $\mathrm{mg} / \mathrm{kg} \mathrm{BW})$ & 4 & $31.5 \pm 5.97$ & $32(24-38)$ \\
\hline P3 (Extract RD $1000 \mathrm{mg} / \mathrm{kg} \mathrm{BW})$ & 4 & $29.5 \pm 3.87$ & $29.5(25-34)$ \\
\hline
\end{tabular}

HDL level shows the data was normally distributed so it was analyzed with Anova. It was found that there was no significant differences between groups, the highest HDL level was in P2 group (31.5 \pm 5.97 ) while the lowest was in $\mathrm{P} 1$ group with (28.2 \pm 5.12$)$ as shown as in table 2. 
c. Low density Lipoprotein (LDL)

Table 3. Effect of ethanol extract of Rosa damascena on LDL (mg/dl) in streptozotocin-induced diabetic rats.

\begin{tabular}{|c|c|c|c|c|}
\hline Group & $\mathbf{N}$ & $\mathbf{X} \pm \mathbf{S D}$ & Median (Min-Max) & $\mathbf{P}$ \\
\hline HCG (Health Control Group) & 4 & $10.7 \pm 1.25 \mathrm{a}$ & $11(9-12)$ & \multirow{5}{*}{$0,031 *$} \\
\hline DG (Diabetes Group) & 4 & $29.2 \pm 11.44 b$ & $32(14-39)$ & \\
\hline P1 (Extract RD 250 mg/kg BW) & 4 & $11 \pm 2.44 \mathrm{ac}$ & $10.5(9-14)$ & \\
\hline P2 (Extract RD 500 mg/kg BW) & 4 & $13.2 \pm 1.25 \mathrm{~cd}$ & $13(12-15)$ & \\
\hline P3 (Extract RD 1000 mg/kg BW) & 4 & $11 \pm 2.70 \mathrm{ad}$ & $10(9-15)$ & \\
\hline
\end{tabular}

Noted: superscript showed significance difference between groups with $\alpha=0.05$

Low Density Lipoprotein data was abnormally distributed, therefore Kruskall-Wallis test was carried out and followed with Mann whitney $U$ test to find differences between groups. Table 3 showed that there was significant differences between LDL levels in all groups.

\section{d. Triglyceride}

Table 4. Effect of ethanol extract of Rosa damascena on Triglyceride (mg/dl) in streptozotocin-induced diabetic rats

\begin{tabular}{|c|c|c|c|}
\hline Group & $\mathbf{N}$ & $\mathbf{X} \pm \mathbf{S D}$ & Median (Min-Maks) \\
\hline HCG (Health Control Group) & 4 & $122.2 \pm 13.74 \mathrm{a}$ & $120(108-141)$ \\
\hline DG (Diabetes Group) & 4 & $1179.2 \pm 362.77 \mathrm{~b}$ & $1145(772-1654)$ \\
\hline P1 (Extract RD 250 mg/kg BW) & 4 & $175 \pm 114.4 \mathrm{a}$ & $183.5(49-284)$ \\
\hline P2 (Extract RD 500 $\mathrm{mg} / \mathrm{kg} \mathrm{BW})$ & 4 & $96.7 \pm 44.2 \mathrm{a}$ & $100(43-144)$ \\
\hline P3 (Extract RD 1000 $\mathrm{mg} / \mathrm{kg} \mathrm{BW})$ & 4 & $207.2 \pm 81.9 \mathrm{a}$ & $177(149-326)$ \\
\hline
\end{tabular}

Noted: superscript showed significance difference between groups with $\alpha=0.05$

The lowest triglyceride level was found in group P2 (96.7 \pm 44.2$)$ followed with group P1 (175 \pm 114.4$)$ and $\mathrm{P} 3$ (207.2 \pm 81.9 ). All groups triglyceride value was analyzed with Anova followed with post hoc Tukey HSD. From this test, it was found that there were significant differences between HCG, diabetes group and extract group.

\section{Discussion}

Streptozotocin is a chemical compound which often used to induce diabetes in animal labs. It enters beta pancreas cells through Glucose Transporter 2 (GLUT2) and cause DNA alkylation. This lead to poly ADPrybosilation and make DNA damage which set off beta 
cell necrotizing ${ }^{15}$. Furthermore, mononuclear cells that infiltrate Langerhans islets make the beta cell damage much worse and conduct hyperglycemia ${ }^{15,16}$.

While $\mathrm{T}$ cells and macrophages are infiltrating, adipose cells activating pro inflammation cytokine which makes insulin resistance in adipose tissue. Hormon sensitive lipase are activated and cause triglyceride breakdowns into free fatty acids and glycerol. Free fatty acids went to bloodstream to get to the liver and synthesized into triglyceride again ${ }^{17}$.

In this study we found that Rosa damascena could lowering cholesterol, LDL and triglyceride significantly but not increasing HDL. $250 \mathrm{mg} / \mathrm{KgBW}$ of Rosa damascena extract have better effect in lowering cholesterol $(58.2 \pm 15.19)$ and LDL (11 \pm 2.44$)$ than other doses. On the other hand $500 \mathrm{mg} / \mathrm{KgBW}$ of Rosa damascena extract optimally decrease triglyceride (96.7 \pm 44.2$)$ much better than other doses.

Several in vitro studies on cell culture have shown pancreatic $\alpha$-glucosidase and $\alpha$ amylase inhibition activates by anthocyanins 6,18. Antocyanin were mentioned could increase insulin sensitivity and glucose uptake in vital organs such as muscle and adipose tissue and suppress lipogenic factors ${ }^{19}$. Other study revealed that administration of cyanidine-3-O-glucosidase able to reduce glycerol and free fatty acids released by mouse embryonic cells during hyperglycemia phase ${ }^{20}$. Anthocyanin can also reduce body weight by decreasing levels of SREBP-1 mRNA (Sterol Regulatory ElementBinding Protein) and inhibiting enzyme that synthesize fatty acids and triglycerol ${ }^{21}$.

There are several possibly mechanism of action of Rosa damascena extract in reducing triglyceride and cholesterol in this study. Gholamhusein in 2010 found that Rosa damascena as pancreatic lipase inhibitor. Rosa damascena has been shown to have strong anti porcine pancreatic lipase activity, measured by turbidimetric assay $^{22}$. Another mechanism was Rosa damascena induce the activation of Peroxisome Proliferator Receptor $\gamma(P P A R \gamma)$ in adipose tissue. This condition will deactivate hormone sensitive lipase, breakdown triglyceride and reduce free fatty acids ${ }^{23}$. Rosa damascena also has 3-hydroxy-r-methyl-glutaryl-CoA reductase activity. Another study showed that $0.15 \mathrm{mg}$ $\mathrm{mL}^{-1}$ of rose extract has $60 \%$ inhibitory effect on activity of $H M G-C o A$ reductase ${ }^{24}$.

Although the real mechanism of Rosa damascena as pancreatic lipase inhibitor and HMG-CoA reductase inhibitor are not known yet, Rosa damascena extract is able to control dyslipidemia. All three doses of Rosa Damascena extract showed better effect in lowering cholesterol, LDL and triglyceride.

\section{Conclusion}

The result of this study showed that Rosa damascena ethanol extract can decrease cholesterol, LDL and Triglyceride but not rising HDL in diabetic rats. This anti-hyperlipidemic effect was probably exerted at least by three mechanism including inhibits pancreatic lipase, increase PPAR $\gamma$ and inhibits $H M G$-CoA reductase. Therefore, Rosa damascena extract seems to be great candidate for anti-hyperlipidemic drugs.

Acknowledgements : We would like to thank Department of pharmacology, Faculty of Medicine, Universitas Airlangga, Faculty of medicine, Hang Tuah University for all supports.

Funding : None

Conflict of Interest : None

Ethical Permission : 456/HRECC.FODM/X/2020

\section{References}

1. World Health Organization, Global Report on Diabetes, WHO (2016) 2016: 11-12.

2. Decroli Eva. Diabetes Mellitus type 2. Central Publishing of Internal Medicine Department, Faculty of Medicine, Andalas University (2019): $1-2$

3. Agrawal RP, Ola V, Bishnoi P, Gothwal S, sirohi P, Agrawal R. Prevalence of Micro and Macrovascular Complications and their Risk Factors in Type-2 Diabetes Mellitus. Journal of the association of physicians of india; (2014) 62: pp. 504-508.

4. Lotfy M, Adeghate J, Kalasz H, Singh J, Adeghate E. A Chronic Complications of Diabetes Mellitus: A Mini Review. Current Diabetes Reviews (2017) 13: 3-10.

5. Ozder Aclan. Lipid profile abnormalities seen in T2DM patients in primary healthcare in Turkey: a cross-sectional study. Lipids in Health and Disease 
(2014) vol. 13:183

6. Gholamhoseinian A, H.Fallah H, Sharififar F. Inhibitory effect of methanol extract of Rosa damascena mill. flowers on $\alpha$-glucosidase activity and postprandial hyperglycemia in normal and diabetic rats. Phytomedicine (2009)16: 935-941

7. Nayebi N, Khalili N, Kamalinejad M, Emtiazy M. A systematic review of the efficacy and safety of Rosa damascena Mill. with an overview on its phytopharmacological properties. Complementary Therapies in Medicine (2017) 34: 129-140.

8. Priska M, Peni N, Carvallo L, Dala Ngapa Y. Review: Antocyanins and Their Uses. Chemical Cakra (2018) 6: 79-97.

9. Boskabady MH, Shafei MN, Saberi Z, Amini S. Pharmacological effects of rosa damascena. Iranian journal of basic medical sciences, (2011) 14: 295307.

10. Julianto TS. Indonesian flower Essential Oil (2016) : 115-116.

11. BPS. Indonesian ornamental plants statistic. Indonesian Central Bureau of Statistic (2017): 1118.

12. B Purwanto, P Liben. Animal models in diabetes research. Experimental Animal Research Protocol Series, (2014) : 27-30.

13. Zahedi-Amiri Z, Taravati A, Hejazian L B. Protective Effect of Rosa damascena Against Aluminum Chloride-Induced Oxidative Stress. Biological Trace Element Research (2019) : 120127.

14. Duncan RC, Knapp RG, Miller, MC. Test of hypothesis in population Means. In: Introductory Biostatistics for the health sciences (1977) John Wiley and Sons Inc: 71-96.

15. Gheibi S, Kashfi K, Ghasemi A. A practical guide for induction of type-2 diabetes in rat: Incorporating a high-fat diet and streptozotocin. Biomedicine \& Pharmacotherapy; (2017) 95:605-613.

16. Goyal SN, Reddy NM, Patil KR, Nakhate KT, Ojha S, Patil CR, et al. Challenges and issues with streptozotocin-induced diabetes. A clinically relevant animal model to understand the diabetes pathogenesis and evaluate therapeutics. Chem Biol
Interact (2016) 244: 49-63.

17. Jocken JWE. Adipose Triglyceride Lipase and Hormone-Sensitive Lipase Protein Expression Is Decreased in the Obese Insulin-Resistant State. The Journal of Clinical Endocrinology \& Metabolism, (2007) 92 :2292-2299.

18. Akkarachiyasit S, Charoenlertkul P, Yibchokanun S, Adisakwattana S. Inhibitory activities of cyaniding and its glycosides and synergistic effect with acarbose against intestinal a-glucosidase and pancreatic a-amylase. Int. J. Mol. Sci (2010) 11: 3387-3396.

19. Beatrice Scazzocchio $\mathrm{B}$, Rosaria Varì $\mathrm{R}$, Carmelina Filesi C, Massimo D'Archivio M, Carmela Santangelo $\mathrm{C}$ et al, Cyanidin-3-O- $\beta$ Glucoside and Protocatechuic Acid Exert InsulinLike Effects by Upregulating PPAR $\gamma$ Activity in Human Omental Adipocytes. Diabetes (2011) 60:2234-2244.

20. Guo H, Guo J, Jiang X, et al. Cyanidin-3-Ob-glucoside, a typical anthocyanin, exhibits antilipolytic effects in 3T3-L1 adipocytes during hyperglycemia: Involvement of FoxO1-mediated transcription of adipose triglyceride lipase. Food \& Chemical Toxicology (2012) 9: 3040-3047.

21. Belwal, Tarun, Seyed F, Seyed M, Solomon H. Dietary Anthocyanin and Insulin Resistance: When Food Becomes a Medicine. Nutrients (2017) 9: 1111.

22. Gholamhoseinian A, Shahouzehi B, Sharififar F. Inhibitory effect of some plant extracts on pancreatic lipase. Int J Pharmacol (2010) 6: 705711.

23. Mohammadi A, Fallah H, Gholamhosseinian A. Antihyperglycemic Effect of Rosa Damascena is Mediated by PPAR. $\gamma$ Gene Expression in Animal Model of Insulin Resistance. Iranian Journal of Pharmaceutical Research (2017) 16: 1080-1088.

24. Gholamhoseinian A, Sharifi-Far F, Shahouzehi B. Inhibitory activity of some plant methanol extracts on 3-Hydroxy-3-Methylglutaryl coenzyme a reductase. Int J Pharmacol (2010) 6: 705-711. 